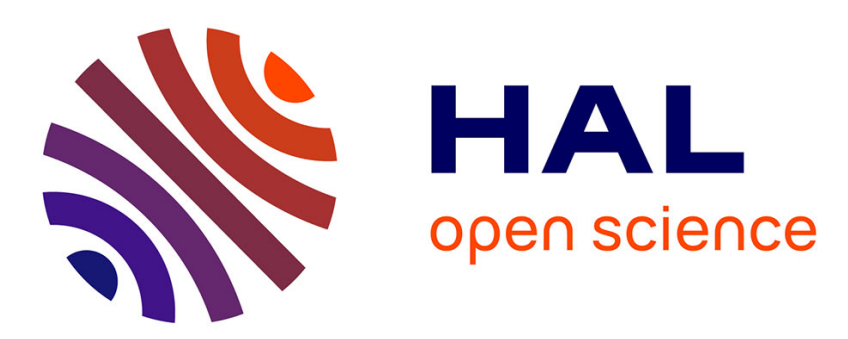

\title{
Analytical solution and numerical simulation of thermocapillary convection in floating zones
}

\author{
G. Chen, Bernard Roux
}

\section{To cite this version:}

G. Chen, Bernard Roux. Analytical solution and numerical simulation of thermocapillary convection in floating zones . Advances in Space Research, 1991, 11 (7), pp.151-162. hal-01309241

\section{HAL Id: hal-01309241 \\ https://hal.science/hal-01309241}

Submitted on 29 Apr 2016

HAL is a multi-disciplinary open access archive for the deposit and dissemination of scientific research documents, whether they are published or not. The documents may come from teaching and research institutions in France or abroad, or from public or private research centers.
L'archive ouverte pluridisciplinaire HAL, est destinée au dépôt et à la diffusion de documents scientifiques de niveau recherche, publiés ou non, émanant des établissements d'enseignement et de recherche français ou étrangers, des laboratoires publics ou privés. 


\title{
Analytical solution and numerical simulation of thermocapillary convection in floating zones
}

\author{
G. CHEN and B. ROUX \\ Institut de Mécanique des Fluides, UMR 34 \\ 1, rue Honnorat, F-13003 Marseille, France
}

\begin{abstract}
The thermocapillary driven flows in a floating zone radially heated by a ring heater are numerically studied in the presence of an axial magnetic field. A closed-form solution(without magnetic field) is obtained by solving a linear(Stokes-type) problem. Steady axisymmetric flows are presented through numerical simulations with a finite-difference method applied to a velocity-pressure-temperature formulation. This work investigates the free surface deformation and its effect on the flow field. The results indicate that the amplitude of free surface deviation from its original shape linearly increases respectively with capillary force and buoyant force. The surface shapes are found to change from convex (curved inward) to concave(curved outward) when Marangoni number exceeds certain value. The effect of magnetic field on the thermocapillary convection is also investigated in this work. The convection intensity can be reduced by a magnetic field. In the presence of a strong axial magnetic field, thermocapillary convection is confined into a thin layer near the free surface.
\end{abstract}

\section{INTRODUCTION}

Thermocapillary convection is a fluid motion driven by surface-tension gradients along a liquid-gas interface, due to the temperature dependence of surface tension. This type of convection plays an important role in the containerless processing of crystals, such as the so-called floating zone method. Theoretical, experimental and numerical efforts have been performed to understand this convection, essentially heat and mass transfer processes driven by temperature gradients. Experimental investigations include those of Chun and Wuest /1/, Schwabe and co-workers $12,3,4 /$, Kamotani et al. /5/. One of the main observation of these investigations has been the transition from steady axisymmetric to timedependent flow under some conditions in the half-floating zone experiments. Numerical studies for steady axisymmetric flows have been conducted by Chang and Wilcox $/ 6 /$, Kobayashi $/ 7 /$, Fowlis and Roberts /8/. The time-dependent axisymmetric flow in Si melt floating zone allowing for the free surface deformation has been studied numerically by Kazarinoff and Wilkowski $/ 9 /$. Three-dimensional time-dependent numerical simulation in a half floating zone configuration has been carried out by Rupp, Müller and Neumann $/ 10 /$ in which the critical Marangoni numbers defining the the transition from steady to time-dependent thermocapillary convection have been determined for a wide range of Prandtl numbers. Recently Shen et al. /11/ computed the energy stability limits of thermocapillary convection in a cylindrical half-floating zone configuration by means of energy stability theory.

This work involves the theoretical and numerical investigation of the thermocapillary driven flows in a full floating zone filled with low Prandtl number melts. The aim is to determine a basic state solution which will be further applied in the bifurcation calculation for locating the onset of oscillatory convection /12/. Most of the calculations are for Si melt with $\mathrm{Pr}=0.023$, and Marangoni numbers are limited to 300 in order to avoid oscillatory regimes according to the results of Rupp, Müller and Neumann /10/.

Adv. Space Res. 11(7), pp. 151-162 (1991) 


\section{PROBLEM FORMULATION}

The numerical modelling of the floating zone configuration is based on the geometry of a liquid bridge as shown in fig.1. The melt zone is heated at the mid-height by an external ring heater with a specified ambient temperature distribution and subjected to the action of a constant axial magnetic field of induction $\mathrm{B}$. The flow may occur in the floating zone from driving forces such as buoyancy force, surface tension(capillary force), and pulling which is ignored in this work. The computational model is developed for an axisymmetric configuration and the free surface(melt-gas interface) is allowed to be deformable. The problem is governed by the hydrodynamic equations(continuity, Navier-Stokes) coupled with energy equation involving Boussinesq approximation. The dimensionless form of these equations for the velocity $U=(u, w)$, the pressure $p$ and the temperature $T$ are

$$
\begin{aligned}
& \frac{1}{r} \frac{\partial(r u)}{\partial r}+\frac{\partial w}{\partial z}=0 \\
& \frac{\partial u}{\partial t}+\operatorname{Re}\left(u \frac{\partial u}{\partial r}+w \frac{\partial u}{\partial z}\right)=-\frac{\partial p}{\partial r}+\nabla^{2} u-\frac{u}{r^{2}}-H^{2} u \\
& \frac{\partial w}{\partial t}+\operatorname{Re}\left(u \frac{\partial w}{\partial r}+w \frac{\partial w}{\partial z}\right)=-\frac{\partial p}{\partial z}+\nabla^{2} w+\frac{G r}{\operatorname{Re}} T \\
& \frac{\partial T}{\partial t}+\operatorname{Re}\left(u \frac{\partial T}{\partial r}+w \frac{\partial T}{\partial z}\right)=\frac{1}{\operatorname{Pr}} \nabla^{2} T
\end{aligned}
$$

with the following boundary conditions

$$
\begin{aligned}
& \text {-at the solid-melt interfaces }(\mathrm{z}=-1,1) \\
& \mathrm{u}=\mathrm{w}=\mathrm{T}=0, \\
& \text {-at the symmetric axis }(\mathrm{r}=0) \\
& \mathrm{u}=\frac{\partial \mathrm{w}}{\partial \mathrm{r}}=\frac{\partial \mathrm{T}}{\partial \mathrm{r}}=0 .
\end{aligned}
$$

The boundary conditions on the free surface are described hereafter.

The free surface $S$ which is represented by a function $\phi(z)$ is not known a priori. To determine this function, we have to impose: i) dynamic boundary condition corresponding to the stress balances, ii) thermal boundary condition involving imposed heat flux due to external radiation and convection. It should be stressed that free surface conditions strongly influence the bulk flow, mainly when thermocapillarity generates surface forces.

The normal stress condition is

$$
-\mathrm{p}+2 \frac{\partial \mathrm{U}}{\partial \mathrm{n}} \cdot \mathbf{n}=\frac{2 \mathrm{H}}{\mathrm{Ca}}(1-\mathrm{CaT})-\frac{\mathrm{Bo}}{\mathrm{Ca}} \mathrm{z} .
$$

The tangential stress condition is

$$
\frac{\partial U}{\partial n} \cdot \tau+\frac{\partial U}{\partial \tau} \cdot \mathbf{n}=-\frac{\partial T}{\partial \tau}
$$

The thermal boundary condition is

$$
\frac{\partial \mathrm{T}}{\partial \mathrm{n}}=\mathrm{S}_{\mathrm{k}}(\mathrm{Ta}-\mathrm{T}) \text {, with } \mathrm{Ta}=\exp \left(-\mathrm{z}^{2} / \mathrm{d}^{2}\right) \text {. }
$$

The kinematic condition is

$$
\mathbf{U} \cdot \mathbf{n}=0 \text {. }
$$

Finally, attachment condition for the free boundary at the melt-solide interfaces is specified:

$$
\phi(-1)=\phi(1)=1 / \mathrm{A} \text {. }
$$

The liquid volume in the floating zone is constant and verifies

$$
\int_{-1}^{1} \phi^{2}(z) d z=2 / A^{2}
$$

where $\mathbf{n}, \tau$ denote the unit outward normal vector and tangent vector on $\mathrm{S}$, respectively. $\mathrm{H}$ is the mean curvature of the surface, defined by

$$
2 \mathrm{H}=\frac{\phi^{\prime \prime}}{\left(1+\phi^{2}\right)^{3 / 2}}-\frac{1}{\phi\left(1+\phi^{\prime 2}\right)^{1 / 2}},
$$

where 'denotes $\mathrm{d} / \mathrm{d} z$. 


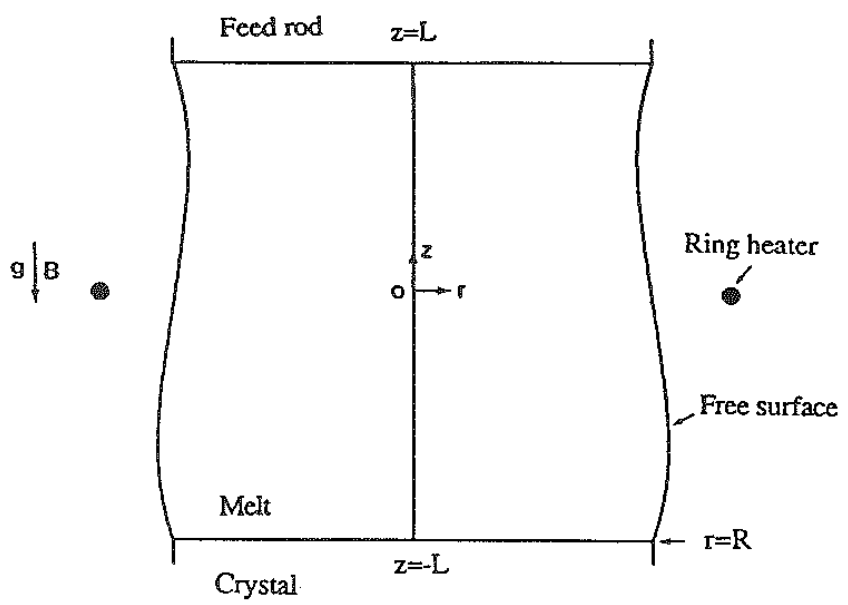

Fig.1 Schematic of floating zone configuration and associated coordinate system

These equations have been made dimensionless by reference to the following scales for length, velocity, pressure $(p+\rho g z)$, and temperature $\left(T-T_{m}\right)$

$$
\begin{aligned}
& \mathrm{L}^{*}=\mathrm{L}, \\
& \mathrm{U}^{*}=\frac{\sigma_{\mathrm{T}} \Delta \mathrm{T}}{\mu}, \\
& \mathrm{P}^{*}=\frac{\sigma_{\mathrm{T}} \Delta \mathrm{T}}{\mathrm{L}}, \\
& \mathrm{T}^{*}=\Delta \mathrm{T} .
\end{aligned}
$$

The dimensionless parameters appearing in the above equations are listed in Tab.I.

TABLE 1 Dimensionless Parameters

$\begin{array}{ll}\text { Aspect ratio } & \mathrm{A}=\mathrm{L} / \mathrm{R} \\ \text { Reynolds number } & \mathrm{Re}=\sigma_{\mathrm{T}} \Delta \mathrm{TL} / \mu \mathrm{v} \\ \text { Marangoni number } & \mathrm{Ma}=\mathrm{Re} \mathrm{Pr} \\ \text { Grashof number } & \mathrm{Gr}=\beta \mathrm{gL}{ }^{3} \Delta \mathrm{T} / \mathrm{v}^{2} \\ \text { Prandtl number } & \mathrm{Pr}=v / \alpha \\ \text { Stark number } & \mathrm{S}_{\mathrm{k}}=4 \varepsilon \sigma *\left(\mathrm{~T}_{\mathrm{m}}\right)^{3} \mathrm{~L} / \mathrm{k} \\ \text { Capillary number } & \mathrm{Ca}=\sigma_{\mathrm{T}} \Delta \mathrm{T} / \sigma_{\mathrm{o}} \\ \text { Bond number } & \mathrm{Bo}=\rho \mathrm{gL} / \sigma_{\mathrm{o}} \\ \text { Hartmann number } & \mathrm{Ha}=\mathrm{BL}\left(\sigma_{\mathrm{e}} / \rho \mathrm{v}\right)^{1 / 2}\end{array}$

Here $B$ is the induction, $g$ is the acceleration due to gravity, $L$ is the half zone height, $R$ is the crystal radius, $\mathrm{Tm}$ is the melting point temperature, $\Delta \mathrm{T}$ is the temperature difference between the maximum heater and melting point temperature, $\alpha$ is the thermal diffusivity, $\beta$ is the volume expansion coefficient, $\varepsilon$ is the emissivity, $k$ is the thermal conductivity, $\mu$ is the viscosity, $v$ is the kinematic viscosity, $\rho$ is the density, $\sigma_{\mathrm{e}}$ is the electrical conductivity, $\sigma_{\mathrm{o}}$ is the surface tension, $\sigma_{\mathrm{T}}$ is the temperature coefficient of surface tension, $\sigma^{*}$ is the Stefan-Boltzmann constant.

\section{ANALYTICAL SOLUTION}

Due to the non-linear character of a free boundary problem, most of the solutions found in the literature are of numerical nature. Only one closed form solution has been given by Da-Riva and Pereira $/ 13 /$ for the half-zone configuration for linearized equations(small Marangoni number). Here we look for a closed form solution in the case of a full floating zone for the purpose, i) to reveal the essentially dynamics of 
the linear flow, and ii) to use this analytical solution as the basic solution for a bifurcation analysis in view of calculating the critical point of transition from steady to time periodic flow.

Analytical solution is found by linearizing eqs(2)-(4). The non-linear terms in the Navier-Stokes and energy equations are neglected. This implies that the analytical solution will be valid only for small Marangoni velocities. By introducing an axisymmetric stream function $\psi$, such as

$$
\mathrm{u}=\frac{\partial \psi}{\partial \mathrm{z}}, \text { and } \mathrm{w}=-\frac{\partial \psi}{\partial \mathrm{r}}-\frac{\psi}{\mathrm{r}},
$$

we have

$$
\left(\nabla^{2}-\frac{1}{\mathrm{r}^{2}}\right)^{2} \psi=\mathrm{Ha}^{2} \frac{\partial^{2} \psi}{\partial \mathrm{z}^{2}}+\frac{\mathrm{Gr}}{\operatorname{Re}} \frac{\partial \mathrm{T}}{\partial \mathrm{r}}
$$

with the following boundary conditions

$$
\begin{array}{ll}
\frac{\partial^{2} \psi}{\partial \mathrm{r}^{2}}+\frac{1}{\mathrm{r}} \frac{\partial \psi}{\partial \mathrm{r}}-\frac{\psi}{\mathrm{r}^{2}}=\frac{\partial \mathrm{T}}{\partial \mathrm{z}}, & \text { for } \mathrm{r}=1 / \mathrm{A} \\
\frac{\partial \psi}{\partial \mathrm{z}}=\frac{\partial^{2} \psi}{\partial \mathrm{z}^{2}}=0, & \text { for } \mathrm{z}=-1,1 .
\end{array}
$$

In the case of $\mathrm{Ha}=\mathrm{Gr}=0$, equation(16) reduces to a biharmonic differential equation which can be solved in terms of biorthogonal series of eigenfunctions $/ 14 /$.

$$
\psi(r, z)=\sum_{-\infty}^{+\infty} \frac{C n}{S_{n}^{2}} I_{1}(r S n) \phi_{1}^{n}(z),
$$

where is $\phi_{1}^{\mathrm{n}}(\mathrm{z})$ is the odd eigenfunctions, associated with the eigenvalues $\mathrm{Sn}$ which are the non-zero roots of $\sin (2 \mathrm{Sn})-2 \mathrm{Sn}=0, \mathrm{I}_{1}$ is the modified Bessel function of first order. The odd functions are defined in /14/. Cn are the coefficients determined by the boundary conditions (17) and (18).

The temperature problem reduces to the solution of the axisymmetric conduction problem with boundary conditions (5) and (9). The solution is straightforward and can be expressed as

$$
T(r, z)=\sum_{0}^{+\infty} a_{n} I_{0}\left(\frac{2 \pi+1}{2} \pi r\right) \cos \left(\frac{2 n+1}{2} \pi z\right),
$$

where $I_{0}$ is the modified Bessel function of zero order , the $a_{n}$ are Fourier coefficients, given by

$$
a_{n}=\frac{S_{k} \int_{-1}^{1} \exp \left(-z^{2} / d^{2}\right) \cos \left(\frac{2 n+1}{2} \pi z\right) d z}{\frac{2 n+1}{2} \pi I_{1}\left(\frac{2 n+1}{2 A} \pi\right)+S_{k} I_{0}\left(\frac{2 n+1}{2 A} \pi\right)} .
$$

The deviation of the free surface from its cylindrical position for the first order approximation can be deduced from the normal-stress condition(7) and the boundary conditions(11) and (12). The final expression is too complicated to be written down here, only some results will be presented hereafter.

\section{NUMERICAL SIMULATION}

Finite-difference method with an alternating-direction implicit formulation(ADI) is used to obtain steady solution. The physical region where the fluid flow occurs is mapped into a rectangular domain by means of a body-fitted coordinate transformation. To give adequate resolution in the boundary layers near the free surface and near the endwalls, a non-uniform mesh is specified as shown in fig.2. The dependent variables $(\mathrm{u}, \mathrm{w}, \mathrm{p}, \mathrm{T})$ are represented by their values on a staggered grid.

Pressure field is obtained from the continuity equation. The total pressure at the previous iterations is used as a first approximation to update the velocity variables. The velocity divergence is then calculated and used to obtain a new pressure field which is then used to correct the velocity. This new pressure field satisfies a Poisson-like equation, which is solved using the sparse-matrix routine DGSS of the ESSL IBM's Scientific Library. 


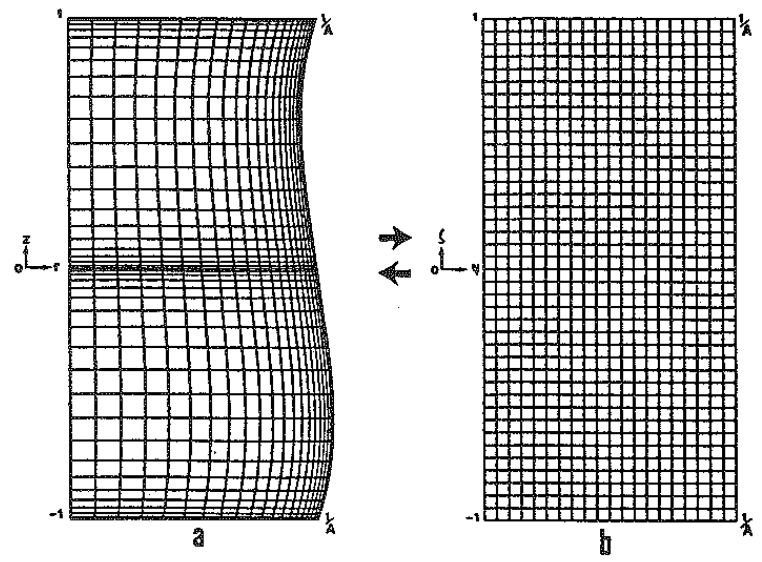

Fig.2 (a) $21 \times 41$ finite difference non-uniform grid in the physical domain $(\mathrm{r}, \mathrm{z})$; (b) corresponding $21 \times 41$ finite difference uniform grid in the transformed domain $(\zeta, \eta)$, with $\Delta \zeta=\Delta \eta$

The computational procedure is as follows:

-outer loop iterations $(m)$ for the free boundary function $\phi(z)$

1. Free boundary function, velocity and scalar fields are known at time $t$, denoted by $\phi^{\mathrm{m}}, \mathrm{U}^{\mathrm{m}, \mathrm{k}}$ $\mathrm{p}^{\mathrm{m}, \mathrm{k}}, \mathrm{T}^{\mathrm{m}, \mathrm{k}}$,

-inner loop iterations(k) for velocity and scalar fields

2. Advance time to $t^{n+1}=t^{n}+\Delta t$, compute predicted velocity $U^{*} m, k+1$ from eqs(3) (4) with boundary conditions (5), (6), (8) and (10),

3. Obtain velocity divergence $\nabla \cdot \mathrm{U}^{* \mathrm{~m}, \mathrm{k}+1}$ and corrected pressure $\mathrm{p}^{\mathrm{m}, \mathrm{k}+1}$ by solving

$$
\nabla^{2}\left(\mathrm{p}^{\mathrm{m}, \mathrm{k}+1}-\mathrm{p}^{\mathrm{m}, \mathrm{k}}\right)=\frac{2}{\Delta \mathrm{t}} \nabla \cdot \mathrm{U}^{* \mathrm{~m}, \mathrm{k}+1}
$$

4. Correct velocity from $U^{\mathrm{m}, \mathrm{k}+1}=\mathrm{U}^{* \mathrm{~m}, \mathrm{k}+1}-\frac{\Delta \mathrm{t}}{2} \nabla\left(\mathrm{p}^{\mathrm{m}, \mathrm{k}+1}-\mathrm{p}^{\mathrm{m}, \mathrm{k}}\right)$,

5. Solve energy equation(4) with boundary conditions (5),(6) and (9) to obtain $\mathrm{T}^{\mathrm{m}, \mathrm{k}+1}$,

6. Repeat process (2)-(5) until the convergence condition is satisfied,

7. Calculate a new free boundary functions $\phi^{\mathrm{m}+1}$ from eq( $(7)$ using the current values with boundary conditions (11) and (12),

8. Repeate the process (1)-(7) until the convergence condition is satisfied.

Note that a time-dependent solution can be obtained from process(2)-(6), if the free boundary function $\phi(z)$ is fixed $(\phi(z)=1 / A$, for example, which implies that the surface is cylindrical).

Convergence is achieved for the outer loop in typically less than 10 iterations for a relative error of $10^{-5}$ for the free boundary function $\phi(\mathrm{z})$. For the inner loop from 200 to 5000 total iterations for a relative error of $10^{-4}$ for variables $(\mathrm{u}, \mathrm{w}, \mathrm{p}, \mathrm{T})$ can be required, depending on the parameters of the problem and the mesh employed. All the numerical results presented in this paper were obtained using a $31 \mathrm{x}$ 61 (radial $x$ axial mesh points) non-uniform grid. The CPU time required to calculate a steady solution for a moderate Marangoni number on an IBM 3090-VF computer for the $31 \times 61$ non-uniform mesh using double-precision arithmetic is about 80 seconds.

\section{RESULTS}

\section{Analytical Results}

The flow patterns and temperature fields obtained analytically are presented in fig.3. Two counterrotating toroidal flow cells appear. The fluid flows from the center to each interface along the free surface and returns along the axis with each cell center near the free surface. The flow cells are 
symmetric about the mid-height between two interfaces and do not mix each other, this is due to the symmetric thermal condition of ambient temperature distribution. This typical flow configuration is well known from experimental work and other numerical simulations. The temperature field is, of course, the conduction solution alone, which is not coupled with the velocity field. To check this analytical solution, we first computed an effectively linear flow by taking a small temperature difference $\Delta \mathrm{T}=0.01 \mathrm{~K}$, corresponding to a Marangoni number $\mathrm{Ma}=16$, for $\mathrm{Ha}=\mathrm{Gr}=0$. Identical results were obtained for the temperature field. Very good agreement was obtained for the velocity field and the pressure. Comparison of the analytical and numerical results for $A=1,2 \mathrm{~L}=2 \mathrm{~cm}, \mathrm{Sk}=2$ and $\mathrm{Gr}=0$ at $\mathrm{Ma}<300$ is given in fig.4. For Ma 30 , The relative difference of the maximum axial velocity between the analytical and numerical results is more than $25 \%$, but the temperature fields are still conduction dominant in a wide range of Marangoni numbers as shown in fig.4(b), Therefore, for Ma $>30$, this analytical solution no longer represents quantitatively the flow fields, numerical simulations are needed.

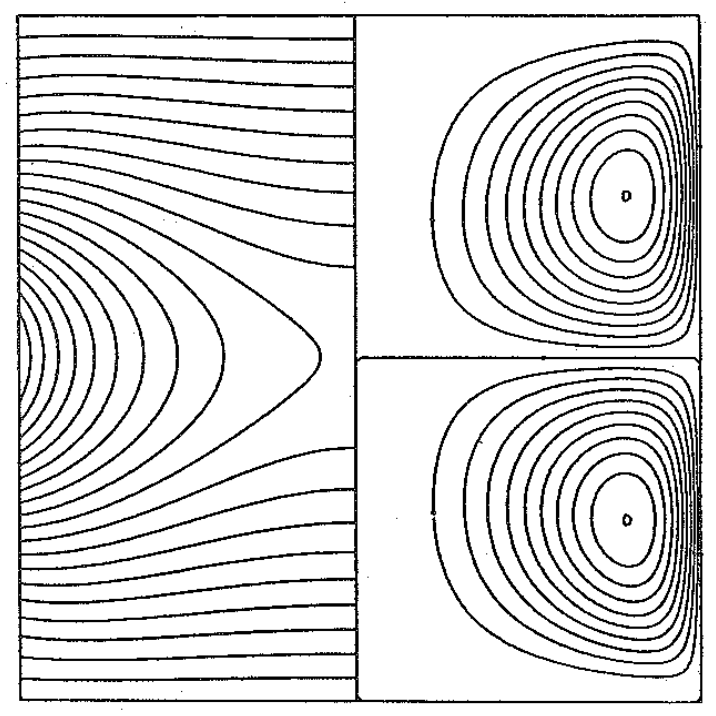

Fig.3 Analytical solution for the stream function(right half) and temperature contours(left half), $\Psi_{\max }=8.89 \times 10^{-3}, \Psi_{\min }=-8.89 \times 10^{-3}, \mathrm{~T}_{\max }=0.575, \mathrm{~T}_{\min }=0$. The contours in these figures, as in all the contour plots presented in this paper, are equally spaced between the maximum and the minimum values of the variable concerned
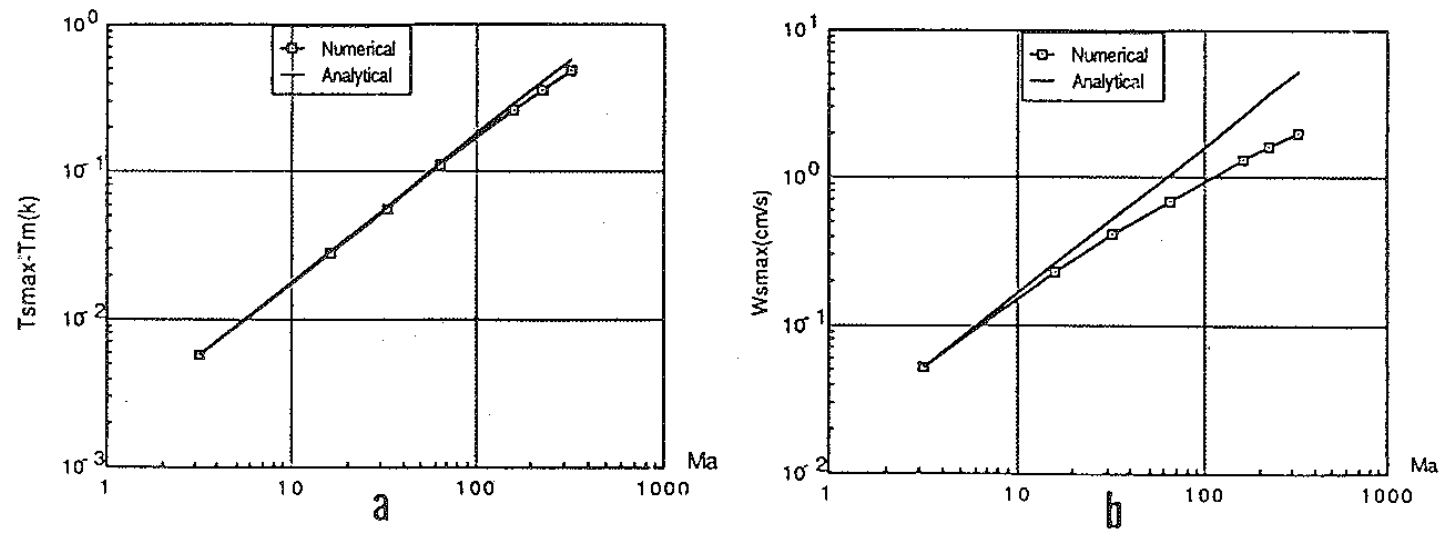

Fig. 4 Comparison of analytical and numerical results for $A=1, B o=G r=0, C a=1.0 \times 10^{-3}$ versus Marangoni numbers, (a) Maximum temperatures(above the melting point) on the free surface; (b). Maximum velocities on the surface 
Since the zone is subjected to the heat flux condition and the melt gains the energy through heat exchange from the heater, influence of Stark number on the temperature field is obviously strong, its influence on the velocity field is also expected to be the same as on the temperature field, since only the surface tension which is connected directly with the surface temperature distribution is the driving force of flow. In fig.5 (a) and (b) the temperature distributions and the axial velocities along the surface are presented for different Stark numbers.
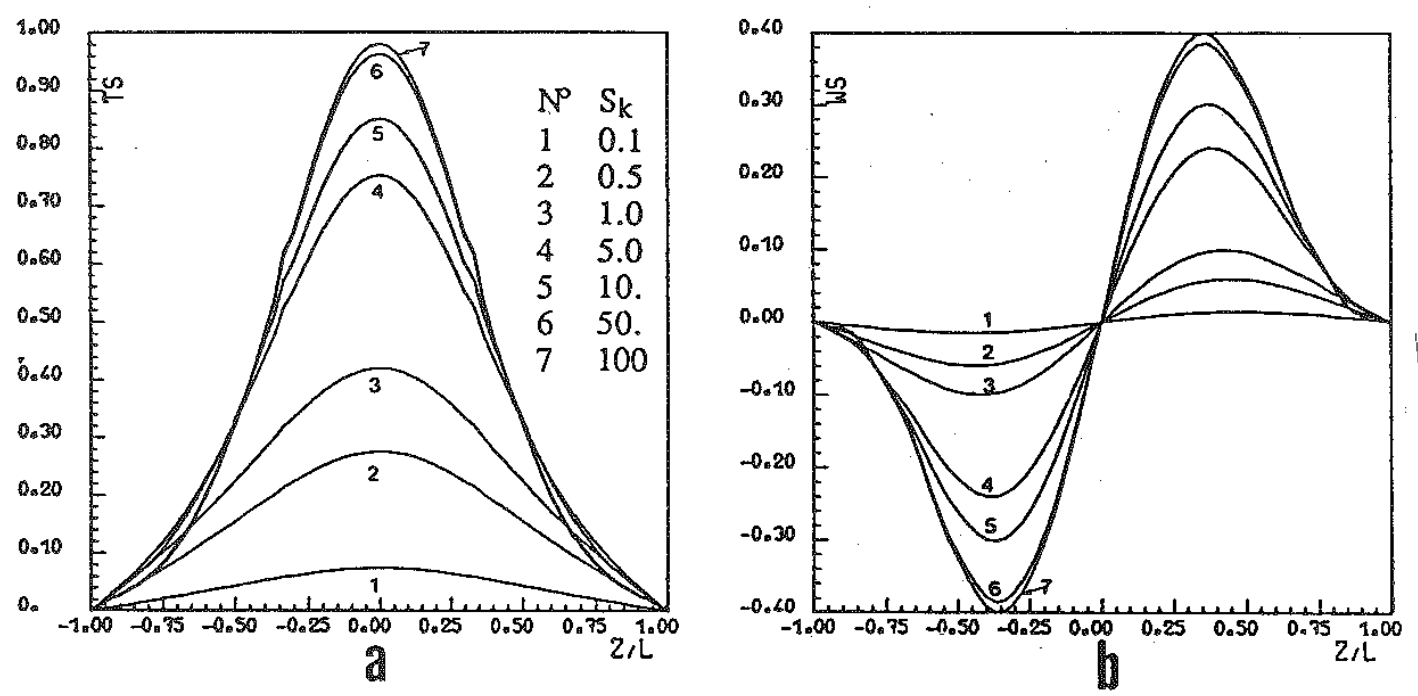

Fig.5 Influence of Stark number on (a) dimensionless surface temperature distributions; (b) dimensionless axial velocities along the surface, for $A=1$

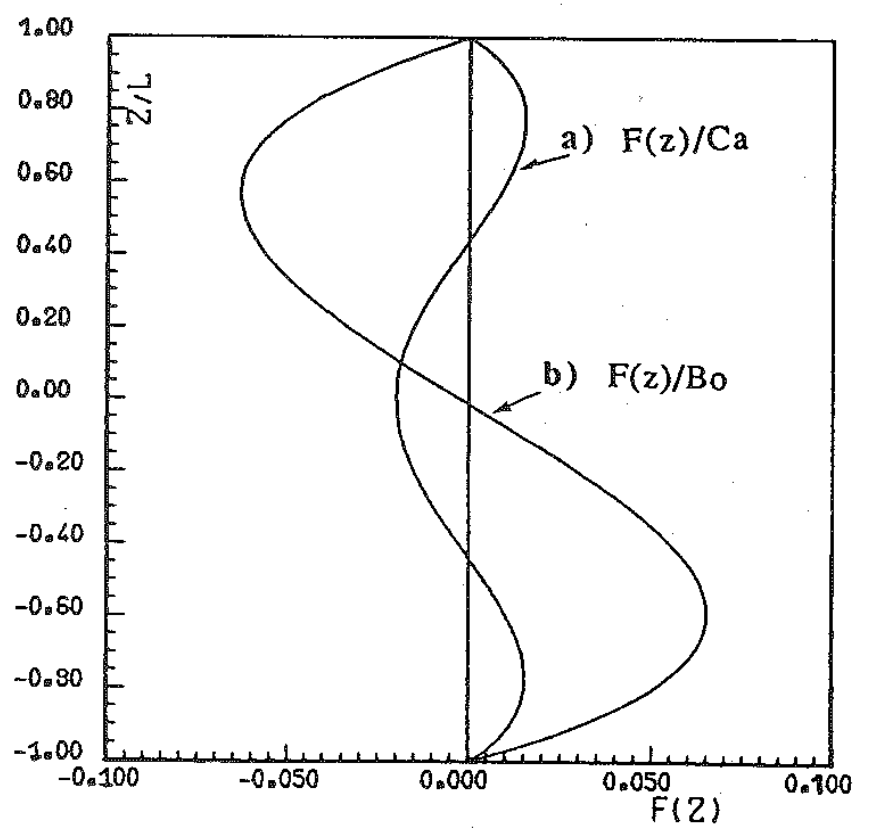

Fig.6 Surface deviation $F(z)$ from its original cylindrical shape, for $A=1, S k=2$, (a) $B 0=0, F(z)$ is divided by capillary numbers; (b) $\mathrm{Ca}=1.0 \times 10^{-3}, \mathrm{~F}(\mathrm{z})$ is divided by Bond numbers

The surface shape based on the pressure distribution obtained from flat surface calculations is presentedin fig.6, in which $F(z)$ is the surface deviation from its original cylindrical position, defined as $F(z)=\phi(z)$ 1/A. In the absence of gravity, i.e. $B O=0$, the surface is convex(curved inward) in the center of the zone(hot region) and is concave(curved outward) near the endwalls(cold region), as shown in fig.6(a). This shape is a typical free surface deformation generated by the surface tension. The amplitude of the 
deviation $F(z)$ linearly increases with the capillary force characterized by the Capillary number, with maximun amplitude $(\mathrm{F}(\mathrm{z}) / \mathrm{Ca}) \max =1.52 \times 10^{-2}$, and minimun amplitude $(\mathrm{F}(\mathrm{z}) / \mathrm{Ca}) \min =-2.01 \times 10^{-2}$. In The presence of gravity force, the surface shape is determined essentially by the action of hydrostatic pressure, while influence of capillary force is relatively small. The surface shape is shown in fig.6(b), with maximun amplitude $(\mathrm{F}(\mathrm{z}) / \mathrm{Bo}) \max =6.41 \times 10^{-2}$ (in the lower part), and minimun amplitude $(\mathrm{F}(\mathrm{z}) / \mathrm{Bo}) \mathrm{min}=-6.41 \times 10^{-2}$ (in the upper part).

\section{Numerical Results}

Numerical simulation has been performed in the following parameter range: $0<\mathrm{Ma} \leq 300,10^{-4} \leq \mathrm{Ca} \leq 0.3$, $0 \leq \mathrm{B} 0 \leq 0.8, \mathrm{Gr} \leq 10^{4}$, while the values of $\mathrm{A}=1, \mathrm{Sk}=2$ are fixed in the calculations. Most of the calculations are for Si melt with $\operatorname{Pr}=0.023$.

The flow patterns and the temperarure field have to some extent the same configuration as obtained by anlytical solution, but it should be pointed out that as $\mathrm{Ma}$ increases, convective effects cause higher temperature gradients on the surface near the endwalls(cold region), hence creating sharp velocity gradients there. These sharp temperature and velocity gradients on the cold corner regions require a very fine mesh to accurate resolution. Another feature of thermocapillary flow at high Marangoni number is the appearence of secondary vortex near the axis on the cold endwalls and on the mid-plane. As Ma $>160$, there appear a counter circulating secondary flow near the axis and the endwalls, When $\mathrm{Ma}=300$, two counter circulating secondary flow near the axis and endwalls and mid-plane were found. The maximum of axial velocity on the axis is $10 \%$ order of that on the free surface.

In the calculations the emphasis is paid to the surface deformation and its effect on the velocity field, therefore the results obtained numerically concerning the computation of surface shape will be presented hereafter.

Calculated shapes of free surface generated by capillary force for Marangoni numbers $M a=1,5,10100$ and 200 are presented in fig.7(a) and (b), revealing different free surface deformations when Marangoni number is varied. The shapes are symmetric about the mid-plane of the zone, and are found to change from convex to concave when $\mathrm{Ma}$ is greater than 5 . For Ma $\leq 2$ the flow is effectively linear, the same shape as the analytical result presented in fig.6(a) is obtained. As Ma increases, the surface in the center of zone moves towards outside with maximum deformation there. The maximum amplitude of deviation $\mathrm{F}(\mathrm{z}) \max$ is found to linearly increas with Capillary number for a given Marangoni number as shown in fig.8(a). The effect of the surface deformation on the velocity field is presented in fig.8(b) in which the maximum velocity in the surface(in the bulk, too) (Vmax)d obtained for deformable surface is divided by the value $(V \max )_{p}$ obtained for non-deformable surface. For $\mathrm{Ma}=300, \mathrm{Ca}=10^{-2}$, the maximum dimensionless surface deformation is of order of $10^{-3}$, the relative error between $(V \max )_{\mathrm{d}}$ and $(\mathrm{V} \max )_{\mathrm{p}}$ is about $5 \%$, while for $\mathrm{Ma}=300, \mathrm{Ca}=0.3$, the surface deformation is significant, causing a relative error of $17 \%$ between $(V \max )_{\mathrm{d}}$ and $(\mathrm{Vmax})_{\mathrm{p}}$. In fig.10(a) we present a typical flow configuration and temperature field with the free surface deformation for a relative high Marangoni number $\mathrm{Ma}=300$ and a high Capillary number $\mathrm{Ca}=0.3$. The influence of gravity force on the surface deformation is presented in fig. 9 for $M a=50,100$ and 200 , when $\mathrm{Ma}>300$ and Bo>0.8, the solution broke down and non-converged solution was obtained. The maximum surface deformation has been found to be a linear increasing function of Bond number. The flow field and the temperature field in the presence of gravity with $\mathrm{Gr}=10^{4}$, and $\mathrm{BO}=0.8$ for $\mathrm{Ma}=200, \mathrm{Ca}=10^{-3}$, is presented in fig. $10(\mathrm{~b})$. Notice that the flow is nearly symmetrical about the mid-plane, although action of buoyancy force in the zone is non-symmetric. This is true for low Prandtl number melts such as Si with $\mathrm{Pr}=0.023$. For fluids with relative high Prandtl number, however, this flow configuration would be changed. In fig. 11 we present the flow patterns and the corresponding temperature fields for two different Prandtl numbers, $\operatorname{Pr}=0.068$ in fig.11(a), and Pr=1 in fig.11(b), respectively. 

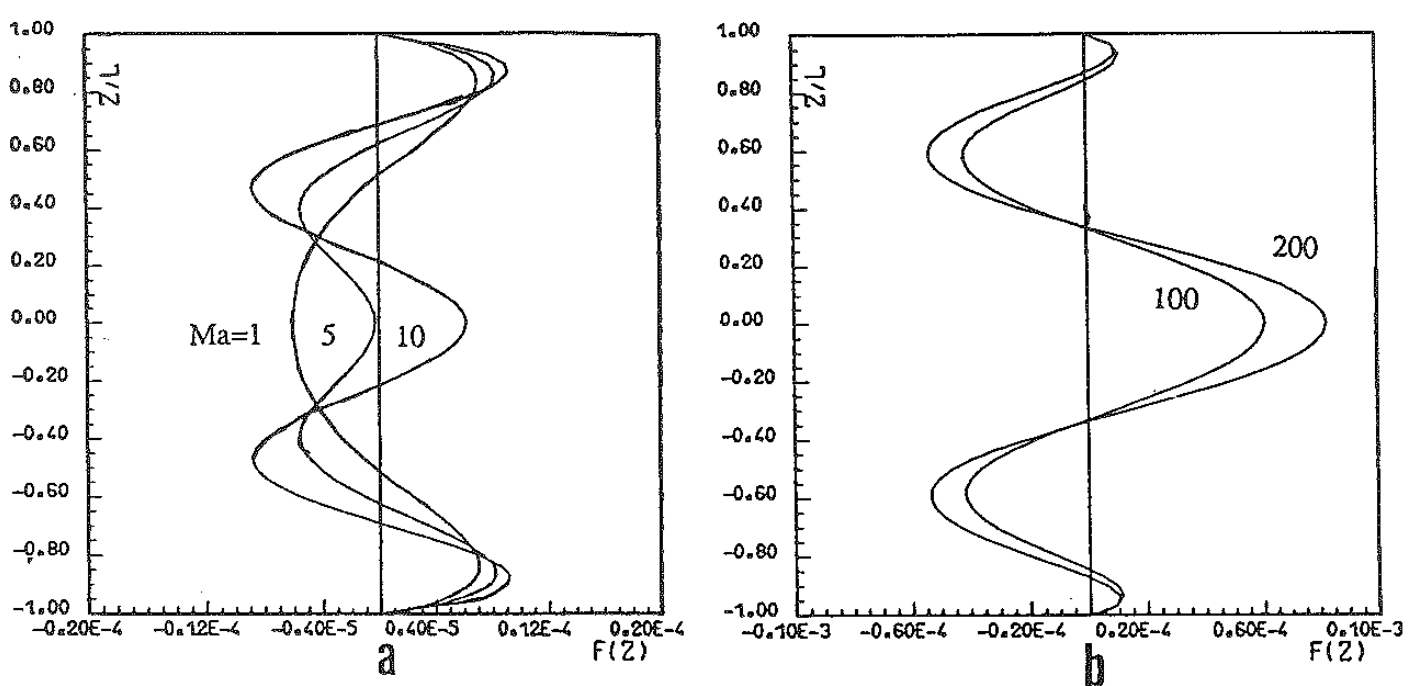

Fig.7 Surface deviation $F(z)$ from its original cylindrical shape, for $A=1, S k=2, C a=1.0 \times 10^{-3}$, $\mathrm{BO}=\mathrm{Gr}=0$, (a) $\mathrm{Ma}=1,5$ and 10 ; (b) $\mathrm{Ma}=100$ and 200
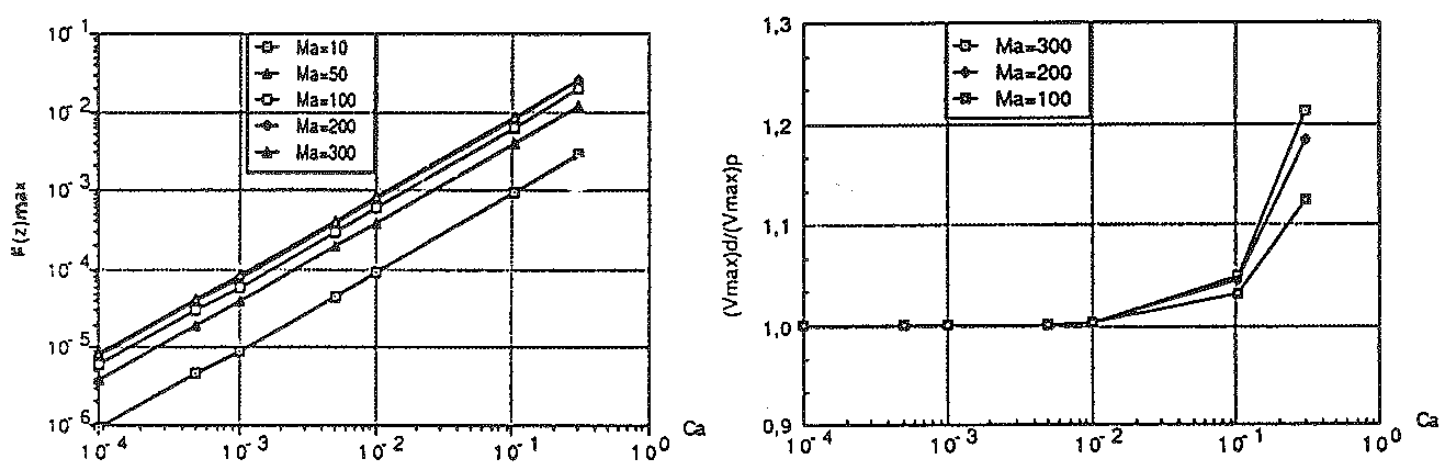

Fig.8 (a)Maximun free surface deformations $F(\mathrm{z}) \max$ versus Capillary numbers for various Marangoni numbers; (b) maximum velocities divided by the corresponding values for nondeformed case

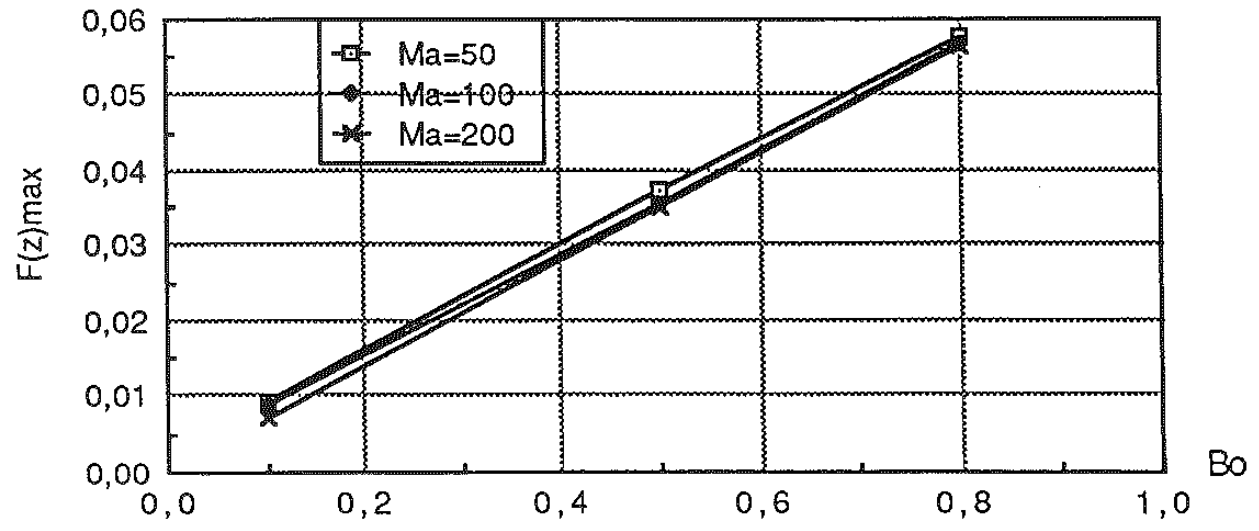

Fig.9 Influence of gravity on the maximum free surface deformations $F(z)$ max for $A=1, S k=2$, $\mathrm{Ca}=10^{-3}, \mathrm{Gr}=10^{4}, \mathrm{Ma}=50,100$ and 200 

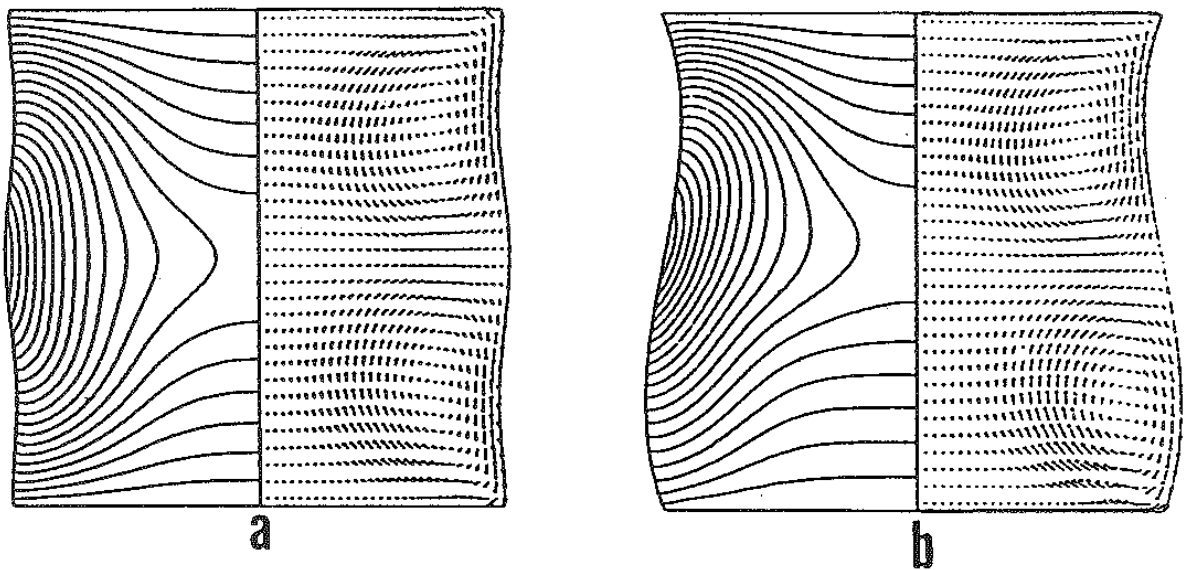

Fig.10 Flow fields(right half) and temperature contours(left half) in a floating zone(deformable surface) for $A=1, S k=2$, (a) $M a=300, C a=0.3, G r=0, V_{\max }=0.0490, T_{\max }=0.520, T_{\min }=0$; (b) $\mathrm{Ma}=200, \mathrm{Gr}=1.0 \times 10^{4}, \mathrm{Bo}=0.8, \mathrm{Ca}=1.0 \times 10^{-3}, \mathrm{~V}_{\max }=0.0533, \mathrm{~T}_{\max }=0.489, \mathrm{~T}_{\min }=0$
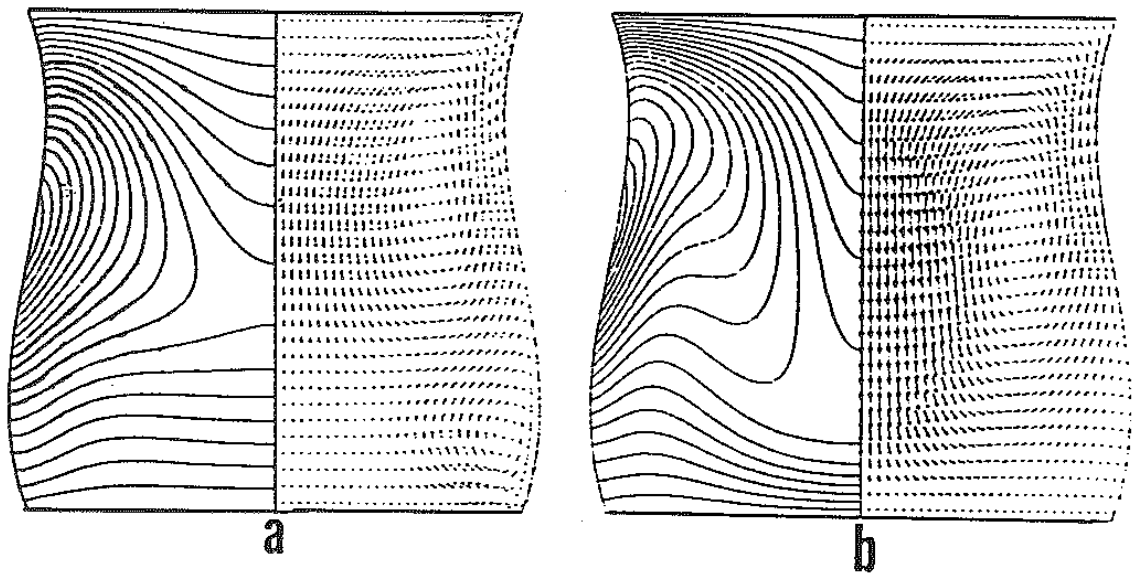

Fig.11 Prandtl number dependence of flow fields (right half) and temperature contours(left half) in a floating zone(deformable surface) for $\mathrm{A}=1, \mathrm{Sk}=2, \mathrm{Bo}=0.8, \mathrm{Ca}=1.0 \times 10^{-3}, \mathrm{Ma}=200, \mathrm{Gr}=1.0 \times 10^{4}$ (a) $\operatorname{Pr}=0.068, \mathrm{~V}_{\max }=0.0604, \mathrm{~T}_{\max }=0.505, \mathrm{~T}_{\min }=0$; (b) $\mathrm{Pr}=1, \mathrm{~V}_{\max }=0.132, \mathrm{~T}_{\max }=0.411$, $\mathrm{T}_{\min }=0$

\section{Thermocapillary Convection with Magnetic Fields}

Application of a constant magnetic field is used to reduce the convection intensity in the melt zone. This technique has been successfully used in a ground-based technology for manufacturing some types of highly perfect semiconductors and was first carried out on board automatic satellite Cosmos-1841 in $1987 / 15 /$. The effect of magnetic field on the thermocapillary convection is characterized by the Hartmann number, as defined in Tab.1, due to the magnetic induction B.

Fig. 12 shows the flow patterns and temperature fields for various Hartmann numbers at $M a=300$, $\operatorname{Pr}=0.023$. The total kinetic energy of the radial velocity field for various Marangoni numbers divided by this energy for $\mathrm{Ha}=0$ is presented in fig. 13 . One sees that convection intensity is much more reduced and the temperature fields are less distorted when Hartmann number is increased. For Ha> 14, the temperature field becomes conduction dominant, the secondary vortex which appeared in fig.12(a) and (b) has disappeared. There exist only two counter circulating cells in the upper and the lower half zone, respectively, and they are concentrated into a small rcgion near the free surface and the cell centers move towards the endwalls. 

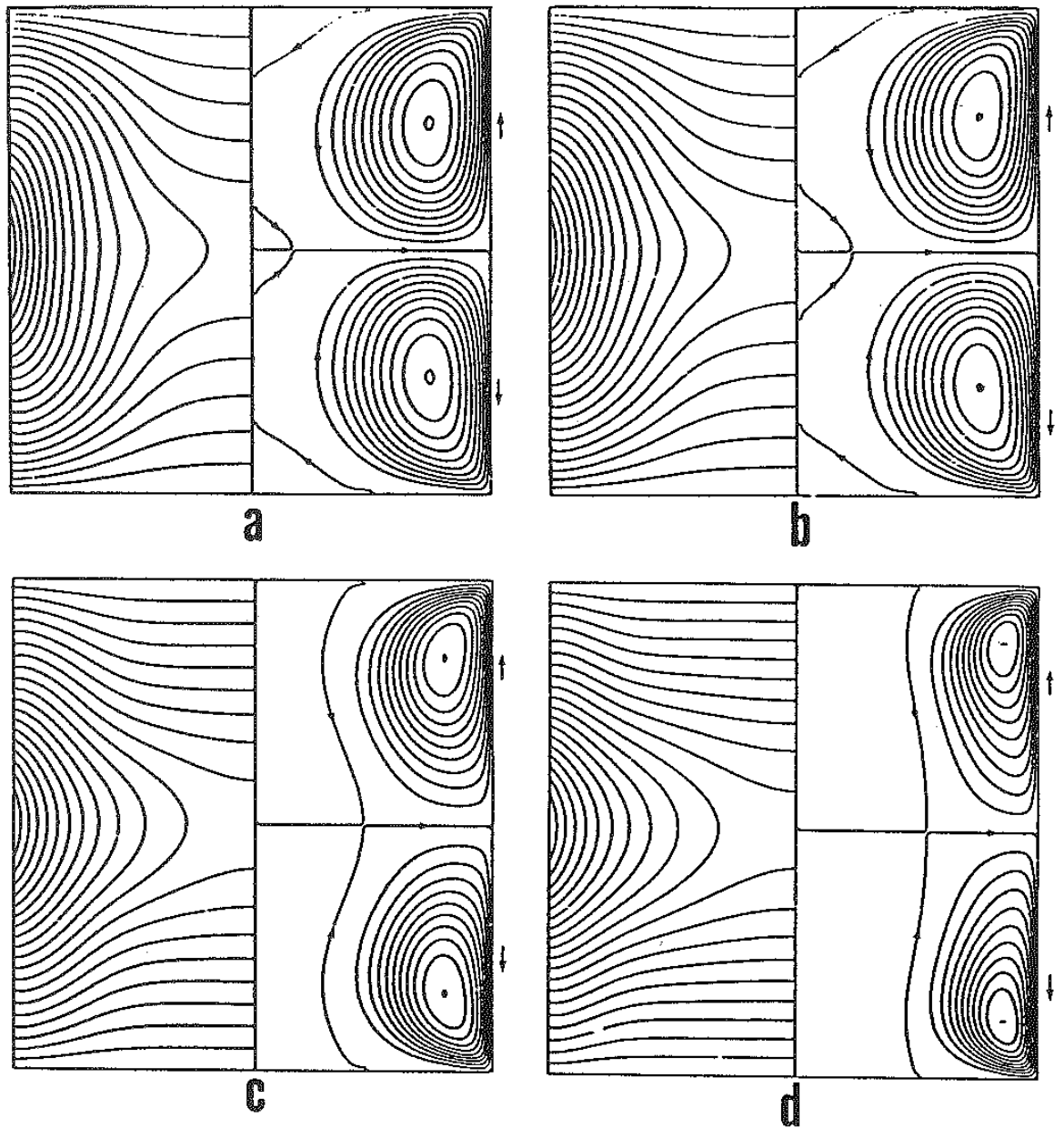

Fig.12 Effect of magnetic field on the thermocapillary flow, shown by stream function(right half) and temperature contours(left half) at $\mathrm{A}=1, \mathrm{Sk}=2, \mathrm{Ca}=1.0 \times 10^{-3}, \mathrm{Ma}=300, \mathrm{Gr}=\mathrm{Bo}=0$

(a) $\mathrm{Ha}=0, \Psi_{\max }=-\Psi_{\min }=0.318 \times 10^{-2}, \mathrm{~T}_{\max }=0.493, \mathrm{~T}_{\min }=0, \mathrm{~F}(\mathrm{z})_{\max }=0.843 \times 10^{-3}$

(b) $\mathrm{Ha}=7.4, \Psi_{\max }=-\Psi_{\min }=0.258 \times 10^{-2}, \mathrm{~T}_{\max }=0.517, \mathrm{~T}_{\min }=0, \mathrm{~F}(\mathrm{z})_{\max }=0.549 \times 10^{-4}$

(c) $\mathrm{Ha}=14.8, \Psi_{\max }=-\Psi_{\min }=0.191 \times 10^{-2}, \mathrm{~T}_{\max }=0.544, \mathrm{~T}_{\min }=0, \mathrm{~F}(\mathrm{z})_{\max }=0.282 \times 10^{-4}$

(d) $\mathrm{Ha}=22.2, \Psi_{\max }=-\Psi_{\min }=0.158 \times 10^{-2}, \mathrm{~T}_{\max }=0.551, \mathrm{~T}_{\min }=0, \mathrm{~F}(\mathrm{z})_{\max }=0.146 \times 10^{-4}$

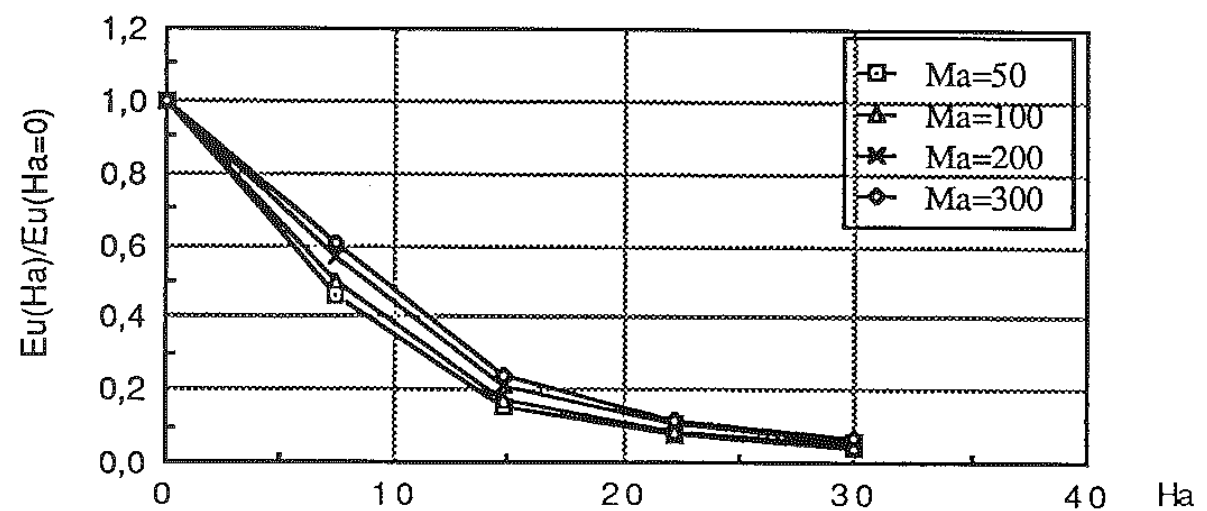

Fig.13 Total kinetic energy of the radial velocity field $E u=$ const $\int_{V} U^{2} d V$ divided by the corresponding value for $\mathrm{Ha}=0$, versus the Hartmann number $\mathrm{Ha}$, for $\mathrm{Ma}=50,100,200$ and 300 , $\operatorname{Pr}=0.023$ 
The effect of magnetic field on the thermocapillary convction in a floating zone configuration has been numerically studied by Baumgartl et al. /16/ for GaAs melt and Si melt, and by Senchenkov $/ 15 /$ for Ge melt. The present results are consistent with their computed results. Following the work of Senchenkov, magnetic field appreciably influences the convection if $\mathrm{Ha}>\left(\frac{\mathrm{Ma}}{\mathrm{Pr}}\right)^{1 / 3}$. This criterion is obtained by estimating a viscous to magnetic forces ratio for a boundary layer at Ha $>1$. In our case of $\mathrm{Si}$ melt with $\mathrm{Pr}=0.023$, if $\mathrm{Ma}$ is chosen equal to 300 , then an appreciable magnetic field would be $\mathrm{Ha}>$ 24 , which corresponds to a magnetic induction B larger than 0.07 Tesla.

\section{CONCLUSION}

We studied theroretically and numerically the thermocapillary convection in a floating zone configuration with deformable liquid-gas interface. A linear(Stokes-type) problem and conduction problem were first solved to obtain a closed form solution for the velocity field and the temperature field. The results were compared with the numerical results obtained by solving the Navier-Stokes and energy equations with a finite difference method, leading to conclude that this analytical solution is valid in the range of Marangoni number below 30, but the temperature solutions are valid in a wide range of Marangoni numbers, typically for Ma<300(for small Pr).

The free surface deformation is numerically computed for a wide range of parameters, such as Marangoni number, Capillary number and Bond number, the shape has been found to change from convex to concave when Ma>2, the amplitude of deformation linearly increases respectively with Capillary number and Bond number. In practice the value of Capillary number is order of $10^{-3}$, the simplification regarding the surface as flat shape would cause a relative error of $5 \%$, but this has been verified only for steady axisymmetric flow in the present computational model, for time-dependent flow the influence of surface deformation on the onset of oscillations has not been suifficiently studied.

The importance of oscillatory thermocapillary convection for crystal growth from a melt has been known for a long time. However, the critical values, such as Marangoni number, aspect ratio, under which the steady thermocapillary convection becomes time-dependent has not yet been accurately determined by numerical studies. Experimental studies of low Prandt number melts are now lacking and more activity in this area is essential. A detailed work of locating the critical values for thermocapillary convection in present configuration is being conducted. We use the bifurcation analysis combined with numerical simulation of steady-state flows which is presented in this paper. This method has been proved to be an efficient tool $/ 17 \%$.

\section{Aknowledgment}

This work is being supported by the Centre National d'Etudes Spatiales(Division Matériaux et Microgravité). The computations were carried out on IBM 3090-VF of CNUSC.

\section{REFERENCES}

1. Ch-H. Chun and W. Wuest, Acta Astron. 6, 1073 (1979).

2. D. Schwabe and A. Scharmann, J. Cryst. Growth 52, 435 (1981).

3. F. Preisser, D. Schwabe and A. Scharmann, J. Fluid Mech. 126, 545 (1983).

4. R. Velten, D. Schwabe and A. Scharmann, Phys. Fluids, to appear.

5. Y. Kamotani, S. Ostrach and M. Vargas, J. Cryst. Growth 66, 83 (1984).

6. C.E. Chang and W.R. Wilcox, J. Cryst. Growth 28,8 (1975).

7. N. Kobayashi, J. Cryst. Growth 66, 63 (1984).

8. W.W. Fowlis and G.O. Roberts, J. Cryst. Growth 74, 301 (1986).

9. N.D. Kazarinoff and J.S. Wilkowski, Phys. Fluids, to appear.

10. R. Rupp, G. Müller and G. Neumann, J. Cryst. Growth 97, 34 (1989).

11. Y. Shen, G.P. Neitzel, D.F. Jankowski and H.D. Mittelmann, submitted to J. Fluid Mech."

12. K.H. Winters, Int. J. Num. Meth. Engng. 25,401 (1988).

13. I. Da-Riva and E.A. Pereira, Acta Astron. Vol. 9, No.4, 217 (1982).

14. D.D. Joseph, L.D. Sturges and W.H. Warner, Arch. Rational Mech. Anal. 78(3), 223 (1982).

15. A.S. Senchenkov, private communication (1990).

16. J. Baumgartl, M. Gewald, R. Rupp, J. Stierlen and G. Müller, ESA SP-259, 47 (1990).

17. B. Roux, G. de Vahl Davis, M. Deville, R.L. Sani and K.H. Winters, in: Notes on Numerical Fluids Mechanics, Vieweg ed., Vol.27, 285 (1989). 